Published in final edited form as:

Subst Use Misuse. 2018 October 15; 53(12): 1997-2002. doi:10.1080/10826084.2018.1451891.

\title{
Implementation of Online Opioid Prevention, Recognition and Response Trainings for Laypeople: Year 1 Survey Results
}

\author{
Janie Simmons ${ }^{a}$, Sonali Rajan ${ }^{b}$, Lloyd A. Goldsamt ${ }^{c}$, and Luther Elliott ${ }^{a}$ \\ aNational Development and Research Institutes, New York, New York, USA

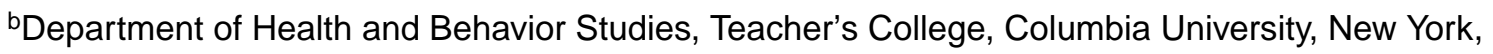 \\ New York, USA \\ "Meyers College of Nursing, New York University, New York, New York, USA
}

\begin{abstract}
Background: This article reports on the first implementation of an online opioid-overdose prevention, recognition and response training for laypeople. The training was disseminated nationally in November 2014. Between 2000 and 2014, U.S. opioid deaths increased by $200 \%$. The importance of complementary approaches to reduce opioid overdose deaths, such as online training, cannot be overstated.
\end{abstract}

Objectives: A retrospective evaluation was conducted to assess perceived knowledge, skills to intervene in an overdose, confidence to intervene, and satisfaction with the training.

\begin{abstract}
Measurements: Descriptive statistics were used to report sample characteristics, compare experiences with overdose and/or naloxone between subgroups, and describe participants' satisfaction with the trainings. Z-ratios were used to compare independent proportions, and paired $t$-tests were used to compare participant responses to items pre- and post-training, including perceived confidence to intervene and perceived knowledge and skills to intervene successfully.
\end{abstract}

Results: Between January and October 2015, 2,450 laypeople took the online training; 1,464 $(59.8 \%)$ agreed to be contacted. Of these, 311 (21.2\% of those contacted) completed the survey. Over $80 \%$ reported high satisfaction with content, format and mode of delivery and high satisfaction with items related to confidence and overdose reversal preparedness. Notably, $89.0 \%$ of participants felt they had the knowledge and skills to intervene successfully post-training compared to $20.3 \%$ pre-training $(\mathrm{z}=-17.2, p<.001)$. Similarly, post-training, $87.8 \%$ of participants felt confident they could successfully intervene compared to $24.4 \%$ pre-training $(\mathrm{z}=$ $-15.9, p<.001)$.

Conclusions: This study demonstrates the effectiveness of the GetNaloxoneNow.org online training for laypeople.

Address for Correspondence: Janie Simmons (simmons@ndri.org), National Development and Research Institutes, 71 West 23rd St., New York, NY 10010 USA.

Contributors

JS and LG designed the study. JS developed the survey questions and analyzed the qualitative data. SR and LG organized and analyzed the quantitative data. JS, SE, LE and LG wrote the manuscript. All authors read and approved the submission of this manuscript to Substance Use and Misuse. 


\section{Keywords}

heroin overdose; opioid overdose; overdose prevention; naloxone; bystanders; online education

\section{Introduction}

In the U.S., opioid-related overdose deaths increased by $200 \%$ between 2000 and 2014 (Rudd, 2015). A total of 47,055 opioid-related overdose deaths were recorded in 2014, an increase of $6.5 \%$ from 2013 and the highest total number of deaths during any year on record. Deaths driven by fentanyl, an extremely potent synthetic, short-acting opioid analgesic (or fentanyl analogues), represent a growing proportion of overdose mortalities in many states (CDC, 2017). Calls to address this dramatic rise in deaths have been met with a range of responses including increasing the availability of overdose prevention, recognition, and response (OPRR) training and expanding the distribution of naloxone, an opioid antagonist effective in reversing respiratory depression (Strauss, M.M. et al., 2013; Bailey and Wermeling, 2014; Doyon et al., 2014; Green et al., 2015; Strang, 2015; Beletsky and Davis, 2017)). All states have passed naloxone community access laws (Davis, 2017).

Evaluations of naloxone programs have consistently demonstrated that training and equipping individuals with naloxone increases overdose-related knowledge and appropriate use of naloxone (Clark et al., 2014). A recent study evaluated take-home naloxone interventions with heroin users and, using public vital statistics records, found that the provision of naloxone "reduced fatal outcomes of overdose among programme participants themselves, their fellow opioid users, and in the wider community" (McDonald and Strang, 2016, pg. 1185). However, despite substantial increases in overdose education and naloxone dispensing among community based programs (Wheeler et al., 2015), opioid overdose deaths continue to rise in the U.S. (Rudd, 2016).

Given the magnitude of the epidemic, the importance of complementary approaches to reduce opioid overdose deaths cannot be overstated. One approach involves offering OPRR training online. A recent pilot of an online training suggests that a web-based platform may be a promising approach to basic overdose education (Roe and Banta-Green, 2016), and such training has been shown to be effective for first responders (Simmons, et al., 2016). This study reports on the first implementation of a comprehensive web-based training for laypeople. Findings describe participant satisfaction with the web-based training and training impact. Subgroup analyses are also reported. For example, to account for the previous experiences of study participants with overdose possibly influencing their response and/or satisfaction to this training, comparisons between participants who reported witnessing an overdose prior to taking the training in comparison to those who had not previously witnessed an overdose are highlighted. Similarly, and to account for possible variations in participant motivation, comparisons on experiences with overdose as well as motivations to take the training between those bystanders who participated in the survey to those who did not participate in the survey are also drawn. 


\section{Materials and Methods}

\subsection{Online Training}

In an effort to extend the reach of existing evidence-based training and dissemination efforts, a team of overdose experts including physicians, nurses, substance use researchers, curriculum designers, illustrators, and animators developed a state-of-the-art, web-based training with funding from the National Institutes for Health, National Institute on Drug Abuse (NIDA). The training was modeled after a face-to-face, best-practice model (Skills and Knowledge on Opioid Overdose or S.K.O.O.P.) developed by the Harm Reduction Coalition in New York and adapted for the web. Computer-assisted instructional models enhance learning and retention (Binder, 1993; Marsch, 2011, 2012). Using animated scenarios and narration provided by voice actors, the training demonstrates how to prevent, recognize, and respond effectively to an opioid overdose, describes barriers to calling emergency services, underscores the importance of remaining at the scene until help arrives, and links learners to additional overdose prevention resources. Trainees who successfully complete a series of interactive quizzes and a 24-question post-test at the conclusion of the 20-minute online training receive a certificate of completion via email.

\subsection{Training Dissemination}

A website, GetNaloxoneNow.org, was developed to house the training and provide additional online resources and information. The training is also supported by a Facebook and Twitter account (Facebook_GetNaloxoneNow; \#GetNaloxoneNow). The training can be accessed without cost at www.GetNaloxoneNow.org. A link to the website was disseminated over the Opioid Safety and Naloxone Network (OSSN) email list in August 2014 to approximately 100 harm reduction activists and scholars throughout the U.S., with a request to help disseminate it widely. In November 2014, the training was approved by the Pennsylvania Department of Public Health and recommended for laypeople. Links to the training were provided on two state websites and recommended in Pennsylvania's Naloxone Standing Order (Pennsylvania Department of Health, 2015).

\subsection{Additional Funding}

Initially, funding for dissemination was non-existent, and website maintenance was provided on a volunteer basis. The Center for Drug Use and HIV Research at NYU School of Nursing provided funding for the evaluation.

\subsection{Data Collection and Study Instrumentation}

2.4.1. Registration Data: All individuals who completed the training provided registration data which included zip code, motivation for participating in the training, source of information about the training, and overdose history. Trainees were able to choose one category that best described their motivation for choosing to take the training. The six categories included: 1) identifying as a concerned community member, 2) identifying as a family member of someone who takes/uses prescription narcotics or heroin, 3) reporting that they themselves take/use prescription narcotics or heroin, 4) identifying as a friend of 
someone who takes/uses prescription narcotics or heroin, 5) having a work-related need, or 6) having another motivation (not already listed).

2.4.2. Survey Data: All participants who agreed to be contacted when registering (between January and October 2015) and who also completed the training were invited to take an online survey in October, 2015. Three follow-up emails were sent to registrants who had not yet responded by November 2015. Participation was voluntary and uncompensated. The National Development and Research Institutes (NDRI, Inc.) Institutional Review Board (IRB) approved a waiver of written informed consent.

2.4.3. Survey Development: A total of 28 survey questions (5-point Likert Scale, multiple choice) were developed to assess perceived knowledge, skills to intervene in an overdose, confidence to intervene, and satisfaction with the training. Trainees were also asked whether they had attempted to obtain naloxone, had succeeded in obtaining it, had experienced barriers to obtaining naloxone, and if they had intervened in an overdose. Although the survey did not explicitly assess knowledge, passing a series of knowledge quizzes - adapted from the Opioid Overdose Knowledge (OOKS) and Opioid Overdose Attitude (OOAS) Scales (Williams et al., 2013)—was required for successful training completion.

\subsection{Data Analysis}

All data were cleaned and organized in Microsoft Excel and subsequently analyzed in SPSS (version 23.0). Descriptive statistics were used to report sample characteristics, compare experiences with overdose and/or naloxone between key subgroups, and describe participant satisfaction with the training. Z-ratios were used to compare independent proportions, allowing comparison of those registrants who elected to be contacted (and did/did not take the survey) across several outcomes (including motivation to participate in the training and self-confidence in intervening in an overdose post-training), while also accounting for differences in group sample size. Motivators participants most frequently endorsed were also compared with participants' experiences with obtaining naloxone. Paired $t$-tests were used to compare participant responses to registration questions to their survey responses, including perceived knowledge and skills to intervene effectively in an overdose emergency. Changes in knowledge and understanding of overdose risks and how to intervene in an overdose emergency were also assessed via paired $t$-tests pre- and post-training.

\section{Results}

\subsection{Registration Data}

Descriptive Results: Between January, 2015 and October, 2015 2,450 laypeople were trained online; the majority (75.9\%) were from Pennsylvania. Of the 2,450 laypeople who accessed the trainings, 1,464 agreed to be contacted. Of these, 311 (21.2\% of registrants) completed the survey.

Comparisons Between Groups: Registration data was used to compare registrants who did not take the survey $(n=2,139)$ with those that did take the survey $(n=311)$, resulting in 
a significant between-group difference on four items. Specifically, more of the bystanders who participated in the survey 1) reported being a family member of someone who takes/ uses prescription narcotics or heroin $(13.3 \%)$ as a motivator for participating in the training in comparison to those registrants who did not participate in the survey $(8.6 \%, \mathrm{z}=3.869, \mathrm{p}$ $<.05)$; 2) reported ever witnessing an overdose (37.9\%) in comparison to those registrants who did not participate in the survey $(29.7 \%, \mathrm{z}=2.948, \mathrm{p}<.05)$, and 3 ) reported ever overdosing $(6.8 \%)$ in comparison to those registrants who did not participate in the survey $(1.84 \%, \mathrm{z}=5.255, \mathrm{p}<.05)$. Conversely, significantly fewer of the bystanders who participated in the survey reported "other" as a motivator for participating in the training $(3.8 \%)$ in comparison to those registrants who did not participate in the survey $(7.8 \%, \mathrm{z}=$ $-2.500, \mathrm{p}<.05$ ). The most common motivation to participate in the training (endorsed by more than $60 \%$ of all training participants and found to be significantly more frequently endorsed in comparison to other motivators $(\mathrm{z}=13.0, \mathrm{p}<.001))$ was that it relates to their work. These data are shown in Table 1.

\subsection{Training Satisfaction}

Training satisfaction ratings (overall satisfaction, format, educational content, animated scenarios, length, level of difficulty) are reported in Table 2. Overall, participants were highly satisfied, with more than $80 \%$ of participants reporting "near complete" or "complete" satisfaction with each aspect of the training. Notably, there was no significant difference in satisfaction with the training between participants who had witnessed an overdose prior to taking the training $(37.9 \%)$ and those who had not.

\subsection{Survey Data Characteristics}

Descriptive Results: Surveys were completed by 311 trainees (21.2\% of those contacted). Residents from all fifty states and the District of Columbia accessed the training. The majority (75.9\%) were from Pennsylvania. Most participants (57.6\%) completed the survey 6-11 months post-training; 42.4\% completed the survey 1-5 months post-training.

\subsection{Training Impact}

Comparison Pre- and Post-Training: Participants were asked at registration and again during the post-training survey whether they felt certain that they had the knowledge and skills needed to intervene effectively in an overdose (Table 3). The percentage of participants who answered affirmatively increased significantly from $20.3 \%$ at registration to $89.0 \%$ on the post-training survey $(\mathrm{z}=-17.2, p<.001)$. Similarly, before the training, only $24.4 \%$ of the participants reported feeling confident they could intervene successfully. After completing the training, $87.8 \%$ felt confident they could successfully intervene $(\mathrm{z}=-15.9, p$ $<.001)$. Notably, $86.5 \%$ of the participants felt they had a better understanding of overdose risks and overdose prevention post-training, and $87.4 \%$ said their understanding of how to intervene in an overdose improved. At least half of the trainees also shared what they learned, with $32.2 \%$ reporting sharing with their co-workers, $44.4 \%$ reporting sharing with their family members, and $50.5 \%$ reporting sharing with others.

In addition, participants who had witnessed an overdose prior to completing the training $(37.9 \%)$ reported significantly higher scores on two items: 1) the feeling that they had the 
knowledge and skills to intervene effectively in an overdose emergency $(t=-4.19, p<$. $001)$; and, 2) feeling confident they could intervene successfully in an overdose emergency to save a life $(t=-3.71, p<.001)$. Following the training, there were no significant differences on either item between these groups. In addition, $5.1 \%$ of the sample reported witnessing an overdose, and 3.9\% intervened (half with naloxone, half without) after completing the training.

Barriers to Obtaining Naloxone.-Most trainees reported being willing to administer naloxone in an overdose event at work (83.9\%) and in their home/community (85.5\%). While $71.7 \%$ of the participants expressed interest in obtaining naloxone post-training, only $30.2 \%$ reported attempting to do so. Reported barriers to obtaining naloxone included: not being sure how to obtain it (16.7\%), inability to get a prescription (7.7\%), lack of availability $(6.8 \%)$, and cost $(7.4 \%)$.

\section{Discussion}

This evaluation yielded findings consistent with those from other evaluations of communitybased overdose response trainings-namely that laypeople feel confident and competent to intervene in opioid overdose emergencies after brief training interventions (Jones et al., 2014; Williams and Strang, 2014; Bagley et al., 2015; European Monitoring Centre for Drugs and Drug Addiction, 2015).

The overwhelming majority of our sample was satisfied or very satisfied with the training's content, format and mode of delivery, suggesting the viability of the internet for these purposes. At least half of the participants reported that they continued to disseminate information learned from the training as well as links to the training itself through these networks. While naloxone was not always available to our participants after they took the training, the survey suggests that they were prepared and motivated to obtain it and willing to administer it in an overdose. However, while the majority of the participants expressed interest in obtaining naloxone post-training, only one-third tried to obtain it. This may be explained, at least in part, by the $30.0 \%$ of participants who stated that they had no need to obtain naloxone because it was available "at work."

This study has limitations which need to be taken into account. Generalizability may be limited due to response bias. Standard survey methodology was adhered to, but limitations in representativeness due to a relatively low response rate may have influenced the results. Participants who had not indicated a preference to be contacted were not contacted; therefore, the analysis was limited in its ability to compare trainees who agreed and did not agree to be contacted. Differential time lapses between when individuals took the trainings and when they filled out the surveys may also have impacted responses. Finally, outcomes were based on self-reported data, not actual measures of behavior change or overdose outcomes as a result of training completion. Future studies should include evaluation of the dissemination and implementation of an enhanced, updated training with more concerted public health marketing, and a more robust evaluation of the impact of the trainings in settings where a certificate of completion from an approved training is required in order to 
obtain naloxone from pharmacies. Studies of actual behavior change and overdose outcomes related to the training are also warranted.

Despite the limitations of the current study and the importance of ongoing research, this study is the first to report on the implementation of a comprehensive web-based opioid OPRR training for lay bystanders by assessing its use, trainee satisfaction, and impact (e.g. increase in perceived knowledge/skills and confidence; motivation to obtain and administer naloxone). The study demonstrates that implementation was effective in Pennsylvania where the training was formally approved and that the intervention is well-suited for rapid expansion. Dissemination in 2015 was accomplished with little advertising (e.g. one national email list and two Pennsylvania state websites). These preliminary findings suggest that online training will constitute an important means of combating the opioid epidemic in the U.S. through educational outreach. Even in states with more developed service infrastructure for people who use opioids, people who are geographically isolated, limited in mobility and/or time, suffer from social anxiety (potentially related to stigma), and/or want to protect the anonymity of peers or family members will benefit from online curricula. Public and private institutions with constraints limiting their ability to provide trainings and purchase naloxone may find online training with a certificate of completion (allowing access to naloxone via pharmacies in states with naloxone standing orders) an advantage as well. In addition, as States Departments of Health grow even more committed to provide overdose prevention, recognition and response training, they can enhance their ability to expand OPRR by extending the reach of community-based trainings via the GetNaloxoneNow.org online trainings (Bystander and professional First Responder).

\section{Acknowledgements}

Many thanks to CDHUR faculty and mentors for their support for this study, and the Pennsylvania Department of Health and Pennsylvania Department of Drug and Alcohol Programs for their support in disseminating the training, as well as others who have helped to disseminate the training nationwide. We also want to thank the experts and CoInvestigators who assisted in writing the scripts and helped to evaluate the training before it was disseminated (Alex Walley, M.D., Sharon Stancliff, M.D., Maya Doe-Simkins, MPH, Michael Dailey, M.D., Sara Jahnke, Ph.D., Todd LeDuc, MS, FACEP and Nabil El Sanadi, M.D. FACEP). Much appreciation is also due to our graphic designer Michael Grabinski of Red 5, Inc. and our webmaster Paul Modiano of Logical Developers, Corp. Finally, many thanks to all who took the time to complete the survey.

\section{Funding}

This evaluation was supported by the Center for Drug Use and HIV Research (CDUHR) with funding from the National Institutes of Health, National Institute of Drug Abuse (Grant \# P30 DA011041). Support to develop the online training was granted by the National Institutes of Health, National Institute of Drug Abuse (Grant \#1R43DA029358-01A1).

\section{References}

Bagley SM, Peterson J, Cheng DM, Jose C, Quinn E, O’Connor PG, Walley AY, 2015 Overdose education and naloxone rescue kits for family members of individuals who use opioids: Characteristics, motivations, and naloxone use. Substance Abuse 36, 149-154 [PubMed: 25564892]

Bailey AM and Wermeling DP, 2014 Naloxone for opiod overdose prevention: pharmacist's role in community-based practice settings. Ann. Pharmacother. 48, 601-606. [PubMed: 24523396]

Beletsky L and Davis C, 2017 Today's fentanyl crisis: Prohibition's Iron Law, revisted. Int. J. Drug Policy, 46, 156-159. [PubMed: 28735773] 
Centers for Disease Control, National Center for Health Statstics, Overdose Death Rates, Accessed at https://www.drugabuse.gov/related-topics/trends-statistics/overdose-death-rates on November 20, 2017.

Clark AK, Wilder CM, Winstanley EL, 2014 A systematic review of community opioid overdose prevention and naloxone distribution programs. J. Addict. Med. 8, 153-163. [PubMed: 24874759]

Davis C, 2017 Prescription Drug Abuse Policy System: Naloxone overdose prevention laws. http:// lawatlas.org/query?dataset=laws-regulating-administration-of-naloxone accessed on November 20, 2017.

Doyon S, Acks SE, Schaeffer S, 2014 Expanding access to naloxone in the United States. Clin. Toxicol (Phila) 52, 989-992.

European Monitoring Centre for Drugs and rug Addiction (EMCDDA), 2015 Preventing fatal overdoses: a systematic review of the effectiveness of take-home naloxone Accessed at http:// www.emcdda.europa.eu/publications/emcdda-papers/naloxone-effectiveness accessed on April 24, 2016.

Green T,Bratberg J, Davis CS, Walley AY, 2015 Orienting patients to greater opioid safety: models of community pharmacy-based naloxone. Harm Reduct. J. Aug. 6; 12:25.

Jones JD, Roux P, Stancliff S, Matthews W, Comer SD., 2014 Brief overdose education can significantly increase accurate recognition of opioid overdose among heroin users. Int. J. Drug Policy 25(1): 166-7. [PubMed: 23773683]

Marsch L, 2011 Computer-assisted HIV prevention for youth with substance use disorders. Subst. Use Misuse 46, 46-56.

Marsch L, 2012 Leverging technology to enhance addiction treatment and recovery. J. Addict. Dis. 31, 313-318. [PubMed: 22873192]

McDonald R and Strang J, 2016 Are take-home naloxone programmes effective? Systematic review utilizing application of the Bradford Hill criteria. Addiction 111(7):1177-87. [PubMed: 27028542]

Pennsylvania Department of Public Health, Standing Order DOH-002-2015 Naloxone Prescription for Overdose Prevention, accessed at http://www.health.pa.gov/My\%20Health/Diseases\%20and $\% 20$ Conditions/A-D/Documents/Naloxone\%20Standing\%20Order\%20for\%20General\%20Public $\%$ 20(2).pdf on August 3, 2016

Roe SS and Banta-Green CJ, 2016 An initial evaluation of web-based opioid overdose education. Subst. Use Misuse 51(2):268-75. [PubMed: 26709867]

Rudd RA, Aleshire N, Zibbell JE, Gladde RM, 2016 Increases in Drug and Opioid Overdose Deaths — United States, 2000-2014. MMWR 64, 1378-1382. [PubMed: 26720857]

Simmons J, Rajan S, Goldsamt L, Elliott L, 2016 Implementation of online opioid prevention, recognition and response trainings for professional first responders: Year 1 survey results. Drug Alc Depend. 169, 1-4.

Strang J, 2015 Death matters: understanding heroin/opiate overdose risk and testing potential to prevent deaths. Addiction Jul;110 27-35.

Strauss MM, Ghitza UE, Tai B 2013 Preventing deaths from rising opioid overdose in the US - the promise of naloxone antidote in community-based naloxone take-home programs. Subst. Abuse Rehabil. 4:65-72.

Wheeler E, Jones TS, Gilbert MK, Davidson P, 2015 Opioid overdose prevention programs providing naloxone to laypersons - United States, 2014. MMWR 64(23), 631-635. [PubMed: 26086633]

Williams AV, Strang J, Marsden J, 2013 Development of opioid overdose knowledge (OOKS) and attitudes (OOAS) scales for take-home naloxone training evaluation. Drug Alcohol Depend. 132, 383-386. [PubMed: 23453260]

Williams AV,MJ,Strang J, 2014 Training family members to manage heroin overdose and administer naloxone: randomized trial of effects on knowledge and attitudes. Addiction 109, 250-259. [PubMed: 24103087] 


\section{Highlights}

- $\quad$ This study assessed the first online opioid overdose training for laypeople.

- Trainees indicate high satisfaction with content, format and mode of delivery.

- Trainees indicate high satisfaction with overdose reversal preparedness.

- Trainees indicate high confidence to intervene in overdose emergencies.

- $\quad$ Findings suggest the effectiveness of the online training. 
Table 1:

Bystander Participant Registration Data

\begin{tabular}{|c|c|c|c|c|}
\hline & $\begin{array}{c}\text { Bystanders } \\
\text { (Participated in } \\
\text { Survey) } \\
\mathbf{N}=\mathbf{3 1 1}\end{array}$ & $\begin{array}{c}\text { Bystanders } \\
\text { (Did Not } \\
\text { Participate in } \\
\text { Survey) } \\
\text { N= 2139 }\end{array}$ & Significance & $\begin{array}{l}\text { All Participants } \\
\quad \mathbf{N}=\mathbf{2 , 4 5 0}\end{array}$ \\
\hline Ever witnessed an overdose & $37.9 \%$ & $29.7 \%$ & $p<.05^{*}$ & $33.8 \%$ \\
\hline Ever overdosed $^{* *}$ & $6.8 \%$ & $1.84 \%$ & $p<.05^{* *}$ & $4.32 \%$ \\
\hline \multicolumn{5}{|l|}{ Motivation for completing training: } \\
\hline Relates to my work & $62.0 \%$ & $65.8 \%$ & $p=.198$ & $63.9 \%$ \\
\hline Concerned community member & $17.9 \%$ & $15.7 \%$ & $p=.302$ & $16.8 \%$ \\
\hline $\begin{array}{l}\text { Family member of someone who takes/uses prescription } \\
\text { narcotics or heroin }\end{array}$ & $13.3 \%$ & $6.9 \%$ & $p<.05^{* * * *}$ & $10.1 \%$ \\
\hline $\begin{array}{l}\text { I take/use prescription narcotics (e.g. Percocet or } \\
\text { Vicodin) or heroin }\end{array}$ & $1.0 \%$ & $0.72 \%$ & $\begin{array}{c}\text { Not Applicable } \\
\text { (insufficient sample } \\
\text { size in at least one } \\
\text { category) }\end{array}$ & $0.86 \%$ \\
\hline $\begin{array}{l}\text { Friend of someone who takes/uses prescription } \\
\text { narcotics or heroin }\end{array}$ & $2.1 \%$ & $1.9 \%$ & $p=.988$ & $2.0 \%$ \\
\hline Other (unspecified) ${ }^{* * * * *}$ & $3.8 \%$ & $7.8 \%$ & $p<.05^{* * * *}$ & $5.8 \%$ \\
\hline \multicolumn{5}{|l|}{$*$} \\
\hline \multicolumn{5}{|l|}{ * $\mathrm{z}=5.255, \mathrm{p}<.05$} \\
\hline \multicolumn{5}{|l|}{ **** $\mathrm{z}=3.869, \mathrm{p}<.05$} \\
\hline ***** $\mathrm{z}=-2.500, \mathrm{p}<.05$ & & & & \\
\hline
\end{tabular}


Table 2:

Summary of Key Satisfaction Data among Bystander Participants

\begin{tabular}{|c|c|c|c|}
\hline Satisfaction with... & $\begin{array}{l}\text { Percentage of } \\
\text { all bystander } \\
\text { respondents } \\
(\mathbf{N}=\mathbf{3 1 1}) \\
\text { reporting } \\
\text { "complete" or } \\
\text { "nearly } \\
\text { complete" } \\
\text { satisfaction. }\end{array}$ & $\begin{array}{c}\text { Percentage of } \\
\text { bystander } \\
\text { respondents who } \\
\text { witnessed an } \\
\text { overdose prior to } \\
\text { taking the training } \\
(\mathrm{N}=118) \text { reporting } \\
\text { "complete" or "nearly } \\
\text { complete" } \\
\text { satisfaction. }\end{array}$ & $\begin{array}{c}\text { Percentage of all } \\
\text { bystander } \\
\text { respondents who did } \\
\text { not witness an } \\
\text { overdose prior to } \\
\text { taking the training } \\
(\mathrm{N}=193) \text { reporting } \\
\text { "complete" or "nearly complete" } \\
\text { satisfaction. }\end{array}$ \\
\hline ...overall training & $87.0 \%$ & $86.2 \%$ & $87.8 \%$ \\
\hline ...format & $84.1 \%$ & $83.6 \%$ & $84.6 \%$ \\
\hline ...educational content & $82.8 \%$ & $83.8 \%$ & $81.8 \%$ \\
\hline ...animated scenarios & $82.1 \%$ & $81.3 \%$ & $82.9 \%$ \\
\hline ...length & $83.2 \%$ & $85.0 \%$ & $81.4 \%$ \\
\hline ...level of difficulty & $81.6 \%$ & $80.0 \%$ & $83.2 \%$ \\
\hline
\end{tabular}


Table 3:

Bystander Participant Data Comparison ( $\mathrm{N}=311)$

\begin{tabular}{|c|c|c|c|}
\hline & $\begin{array}{l}\text { Bystanders } \\
\text { Prior to Training } \\
\text { (Percentage } \\
\text { agreeing with } \\
\text { statement) }\end{array}$ & $\begin{array}{c}\text { Bystanders } \\
\text { Following } \\
\text { Training } \\
\text { (Percentage } \\
\text { agreeing with } \\
\text { statement) }\end{array}$ & Significance \\
\hline $\begin{array}{l}\text { I have the knowledge and skills needed to intervene effectively in an } \\
\text { overdose emergency. }\end{array}$ & $20.3 \%$ & $89.0 \%$ & $p<.001$ \\
\hline $\begin{array}{l}\text { I feel confident that I could intervene successfully in an overdose } \\
\text { emergency. }\end{array}$ & $24.4 \%$ & $87.8 \%$ & $p<.001$ \\
\hline I have a better understanding of overdose risks & No data available & $86.5 \%$ & $\begin{array}{l}\text { Not Applicable (no } \\
\text { comparison group) }\end{array}$ \\
\hline $\begin{array}{l}\text { My understanding of how to intervene in an overdose emergency } \\
\text { improved }\end{array}$ & No data available & $87.4 \%$ & $\begin{array}{l}\text { Not Applicable (no } \\
\text { comparison group) }\end{array}$ \\
\hline
\end{tabular}

Improvements significant at $\mathrm{p}<.001$ 
Table 4:

Barriers to Obtaining Naloxone $(\mathrm{N}=311)$

\begin{tabular}{cc}
\hline Barrier & $\begin{array}{c}\text { Percentage of Bystanders } \\
\text { Reporting Barrier* }\end{array}$ \\
Not being sure how to obtain Naloxone & $16.7 \%$ \\
Inability to obtain a prescription & $7.7 \%$ \\
Lack of Naloxone availability & $6.8 \%$ \\
Cost-prohibitive & $7.4 \%$ \\
\hline
\end{tabular}

Note: Participants could select multiple responses; not all participants reported a barrier 